\title{
Effect of Soaking Treatment on Germination of Hard Coated Tropical Forest Tree Seeds
}

\author{
J. B. Odoi ${ }^{1, *}$, D. Mugeni ${ }^{1}$, R. Kiiza ${ }^{1}$, B. Apolot ${ }^{1}$, S. Gwali ${ }^{1}$ \\ ${ }^{1}$ National Forestry Resources Research Institute, National Agricultural Research Organization. \\ *Corresponding author. (e)+256782568822 @ juventineboaz@gmail.com
}

\begin{abstract}
Seed germination and seedling growth performance of Maesopsis eminii and Terminalia catappa under different water soaking treatments were evaluated for 120 days under nursery conditions. A total of 1400 seeds were pre-treated with hot $\left(95^{\circ} \mathrm{C}\right)$ and cold water (ambient temperature) by soaking for 12,24 and 48 hours with a control of no soaking. The seeds were sown directly into polythene pots filled with uniform growth medium (top forest soil, sand and clay soil mixed in a ratio of 5:3:2) to avoid disturbance of the root system after germination. The seeds were sown in a randomized block design with seven treatments and three replicates. Data were analysed using ANOVA in GenStat v18. Results indicated that soaking enhanced seed germination. Soaking of seeds in cold water for 12 hours resulted into higher germination $(90 \%$ for Terminalia catappa and $85 \%$ for Maesopsis eminii) than the control (48\%). Soaking period and water temperature significantly influenced seedling vigour $(\mathrm{F}$ value $=0.962 ; p=0.038)$. Soaking seeds in cold water for 24 hours enhanced Maesopsis eminii seedling growth by $8.0 \mathrm{~cm}$ Terminalia catappa seedlings by 7.4 $\mathrm{cm}$. Seed dormancy, germination percentage and growth performance in hard coated seeds such as Maesopsis eminii and Terminalia catappa can be broken by soaking in cold water for 12-24 hours. Pre-germination treatments significantly influences the germination and seedling growth.
\end{abstract}

Keywords: Maesopsis eminii, Terminalia catappa, seeds, pre-germination, soaking.

\section{Introduction}

Several indigenous fast-growing tropical tree species possess hard coated seeds which exhibit seed dormancy and low/poor germination. Yet some of these species are important in forest reforestation and afforestation programmes. Terminalia catappa is a large tropical tree in the Leadwood tree family, Combretaceae, which grows mainly in the tropical regions of Asia, Africa, and Australia. Maesopsis eminii, a semi deciduous fast-growing timber tree species of the family Rhamnaceae, exhibits germination difficulties due to the woody hard coated seeds. The fruit is an obovoid drupe, $20-35 \mathrm{~mm}$ long and under the exocarp is a spongy mesocarp and stony endocarp surrounding the seeds. The stony endocarp of Maesopsis eminii and Terminalia catappa hinder water permeability and germination thus presenting hard seed coat dormancy. Such seeds take too long to germinate or have random germination when no pre-germination treatment is applied (Azad et al. 2010a). One such pre-germination treatment is soaking the seed 
in hot or cold water. Several studies have suggested that pre-sowing treatments increase germination of seeds of temperate tree species with less documentation of tropical tree species (Hossain et al. 2005; Azad et al. 2010b). Seed dormancy can be either physiological or physical/mechanical due to water impermeable seed coat and each dormancy type require different pre-treatment method (Olvera-Carrilloa et al. 2003 and Morpeth and Hall, 2000). Presowing treatment is usually geared towards breaking seed dormancy to ensure rapid, uniform and maximum germination (Alamgir and Hossain 2005).

The difficulties experienced by tree nursery operators to germinate the hard-coated tree species poses a serious problem in promoting these species for reforestation and afforestation within the degraded tropical regions. Several mechanisms are in place that can enhance hard coated seed germination for those species that are prone to such dormancy. This study focused on application of soaking treatment to improve the germination of hard coated indigenous tree seeds and guide institutions and individuals engaged in tree nursery operations.

\section{Materials and Methods}

\section{Materials}

A total of 1400 mature ripe fruits of Maesopsis eminii and Terminalia catappa were collected from thirty trees each in December 2015 and transported to the National Forestry Resources Research Institute (NaFORRI) in Kifu, Uganda. The fruits were macerated to soften the fleshy pulp before they were washed in cold water to clean the inert matter. Clean seeds were then placed in a cool $\left(27^{\circ} \mathrm{C}\right)$ open shade to dry for two weeks and later stored in the tree seed store at $\mathrm{NaFORRI}$ at $24^{\circ} \mathrm{C}$ for six months during which the seed developed dormancy.

\section{Experimental Design}

Thirty-three polythene pots were filled with uniformly mixed standard nursery soil consisting of top forest soil, sand and clay at a ratio of 5:3:2. The polythene pots were placed in nursery beds measuring $4 \times 1 \mathrm{~m}$ aligned in the east to -west. The beds were constructed at $1.2 \mathrm{~m}$ on one side, sloping to $1 \mathrm{~m}$ high on the other side to allow workability during watering and data collection while avoiding direct sun rays from hitting directly on to the pots sown with the seeds after pre-sowing treatments. One hundred seeds of each species were soaked in cold and hot water for different durations. The seeds were sown in a randomized complete block design with three replicates to determine the variations among the experimental units. The seeds were subjected to seven pre-sowing treatments including controls thus in total 1400 seeds were subjected to pre-treatments and sowing dates recorded. The experimental soaking treatments comprised the following:

M: Control (Maesopsis eminii seeds without any treatment), H48M: Maesopsis eminii seeds soaked in hot water for 48 hours, H24M: Soaking in hot water for 24 hours, H12M: Maesopsis eminii seeds soaked in hot water for 12 hours, C48M: Maesopsis eminii seeds soaked in cold water for 48 hours C24M: Maesopsis eminii seeds soaked in cold water for 24 hours C12M: Maesopsis eminii seeds soaked in cold water for 12 hours K: Control (Terminalia catappa seeds without any treatment) H48K: Terminalia catappa seeds soaked in hot water for 48 hours 
H24K: Terminalia catappa seeds soaked in hot water for 48 hours H12K: Terminalia catappa seeds soaked in hot water for 48 hours C48K: Terminalia catappa seeds soaked in cold water for 48 hours C24K: Terminalia catappa seeds soaked in cold water for 24 hours

C12K: Terminalia catappa seeds soaked in cold water for 12 hours

The letters C, H, K and M stand for cold water, hot water, Terminalia catappa and Maesopsis eminii respectively.

One hundred seeds from each species were subjected to pre-treatments and replicated seven times $(7 \times 100)$, making a total of 700 seeds based on Rao et al. (2006). One hundred seeds of each species were not soaked to serve as the control. Seeds of Maesopsis eminii and Terminalia catappa were soaked in water for a period of 12, 24 and 48 hours and then dried in direct sun at air temperature of $20.4^{\circ} \mathrm{C}$ for one hour before sowing in soil filled pots (Plate 1). Each pot was about $7.5 \mathrm{~cm}$ in diameter at the bottom and $7.5 \mathrm{~cm}$ in diameter at the top with a volume of about $39.25 \mathrm{~cm}^{3}$ of mixed soil.

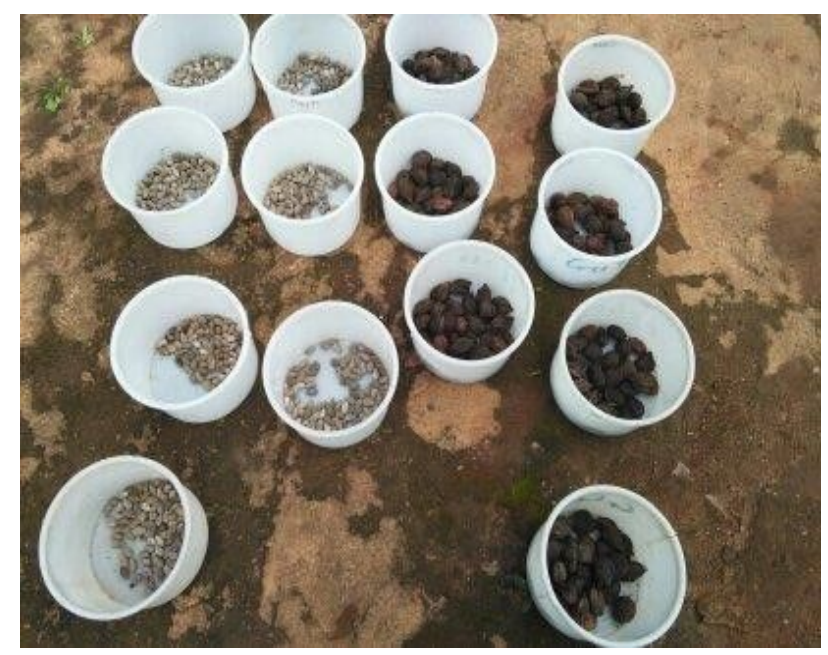

Plate 1. Seed samples before sowing in soil filled pots.

Either cold or hot water was replaced twelve hourly to break and drain germination inhibitors from the seeds and maintain the moisture condition. Each seed sample was sown directly in 3inch flat polythene pots cut to 4 inches long. The pots were filled with uniformly mixed soil (top forest soil $50 \%$ and sand $30 \%$ and clay soil $20 \%$ ) as germination medium. All the seed samples were sown at the same time to a depth of $3-5 \mathrm{~cm}$ and given the same treatment (watering in the morning and evening) for 120 days. Watering was done in the mornings and evenings to avoid minimize evaporation.

\section{Data Collection}

Data on germination were recorded weekly from the time seeds emerged above the soil level starting from the first day of sowing up to a maximum of 120 days. Shoot length and number of leaves were measured fortnightly for four months. Seedlings total height was recorded to the nearest millimetres using a foot ruler while the number of leaves was counted visually. Growth performance of the different treatments was recorded by measuring the height of each seedling 
and counting the number of leaves weekly. Seeds whose shoots emerged from the soil in the pots were considered to have germinated up to 120 days. Other seedlings growth parameters like root collar diameter, leaf width, leaf length, petiole elongation was not recorded to avoid harming the tender seedlings.

\section{Germination Percentage, Germination Energy and Seedling Vigour}

The germination percentage was determined after 120 days from the date of sowing based on Billah et al. (2015) and Maguire (1962). Percentage germination was calculated as: Germination $\%=$ Number of germinated seed/ Number of seeds sown $* 100$. The germination energy of Maesopsis eminii and Terminalia catappa (represented as a factor of the germination percentage by the time taken for germination) was determined to derive the germination rate and the germination vigour of the seeds. Germination energy is a good indicator of seedling vigour in the field. The seedling vigour was visually assessed on the basis of size of leaves, stem size and the seedling health. Data on seed germination percentage and the growth performance were analysed using one-way analysis of variance (ANOVA) in GenStat v18.

\section{Results}

\section{Seed Germination}

There was a significant $(\mathrm{F}$-value $=0.962 ; p=0.038)$ difference in the germination percentages among the treatments. Percentage germination was highest among seeds treated with cold water for 12 hours and 24 hours (86\% and $83.83 \%$ respectively) followed by seeds treated with hot water for 12 hours while seeds treated for 24 hours did not have significant differences in germination percentages $(73 \%$ and $72 \%$ respectively). The percentage germination of seeds treated with hot water for 48 hours was lowest at $70 \%$ (Figure 1).

Terminalia catappa seeds soaked in cold water for 48 hours, control and seeds treated for 24 hours germinated within 41 days after sowing (DAS) while seeds soaked in cold water for 12 hours, 24 hours and hot water for 48 hours germinated within 48 DAS. Seeds soaked in hot water for 12 hours germinated last at 55 DAS.

The highest germination was recorded in seeds soaked in cold water for 12 hours with $82.35 \%$ followed by seeds soaked in cold water for 48 hours and 12 hours both at $76.41 \%$. The percentage germination of seeds soaked in hot water for 12 hours, 24 hours and 48 hours were lowest with 17.75, 41.17 and $35.29 \%$ respectively (Figure 2). 


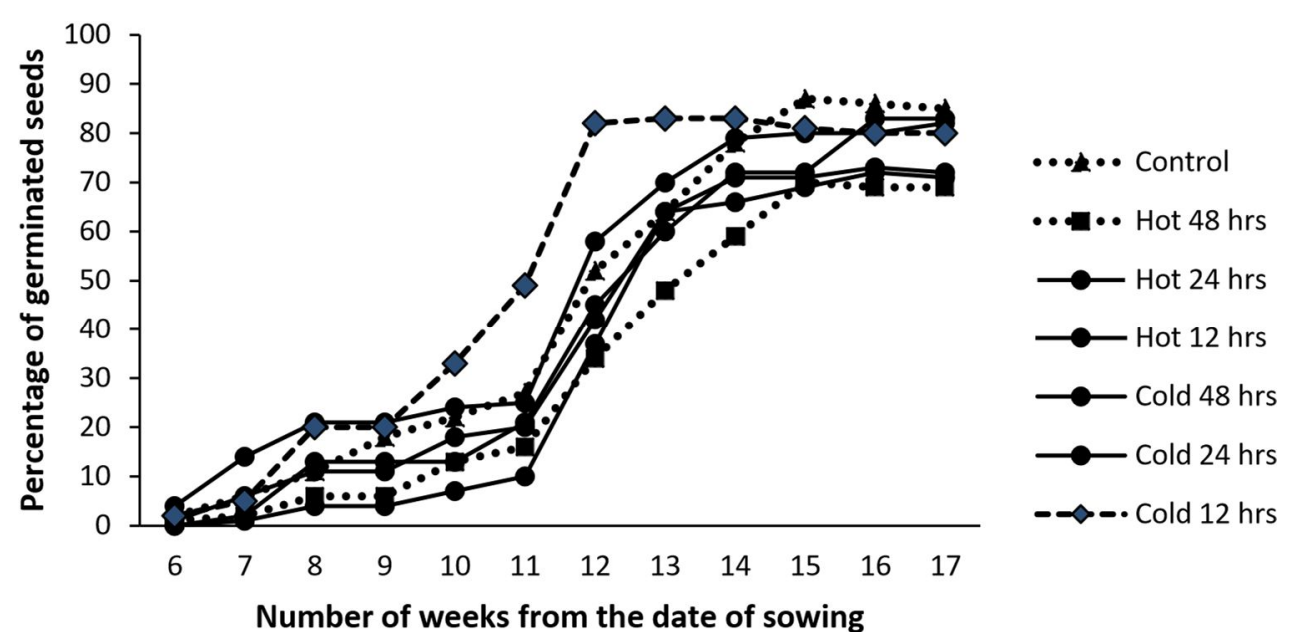

Figure 1. Germination of Maesopsis eminii seeds subjected to different water soaking treatments

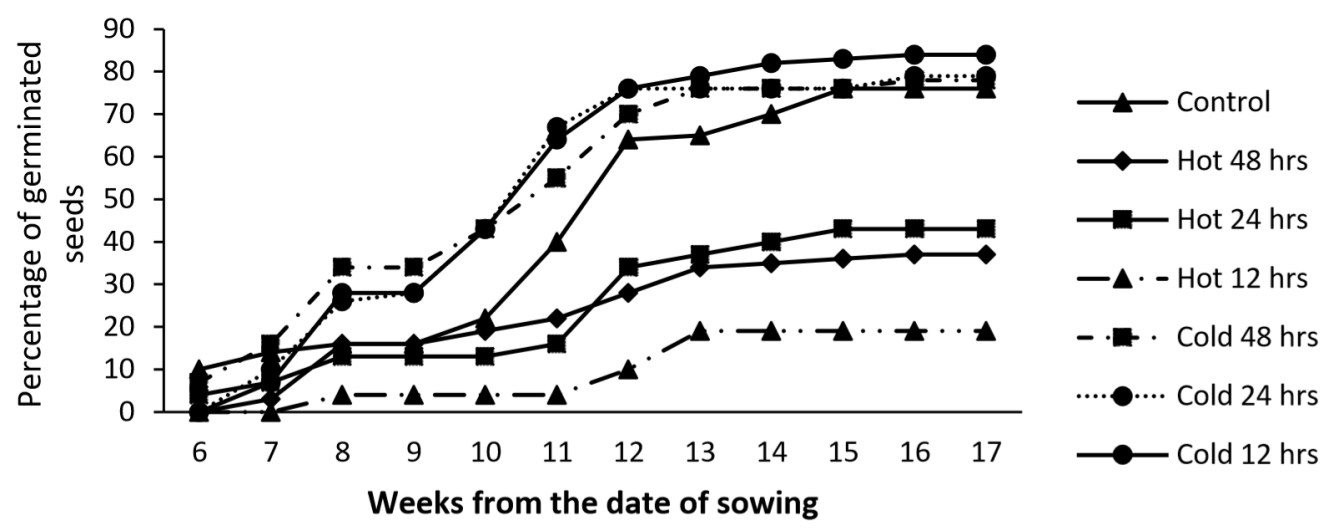

Figure 2. Germination of Terminalia catappa seeds subjected to different water soaking treatments

Soaking Maesopsis eminii and Terminalia catappa seeds with cold water for 12 hours had better germination than all the other treatments (Figures 1 and 2). Soaking hard coated seeds with hot water did not improve their germination beyond the control treatment. Overall, soaking for 48 hours resulted in lower germination than the rest of the treatments.

\section{Seedlings Germination and Growth}

Optimum germination was noted in seeds soaked for 12 and 24 hours with cold water although germination rate dropped after the $11^{\text {th }}$ week. Seeds under control treatment exhibited low germination for several weeks. A total of 544 (78.2\%) Maesopsis eminii seeds germinated out of 696 seeds sown within the seven treatments while $163(68.5 \%)$ Terminalia catappa seeds germinated out of 238 seeds sown. This implies that soaking hard coated seeds in cold water for $12-24$ hours as a pre-germination treatment method enhances seed germination of such species. 
Table 1. Growth performance (mm) of Maesopsis eminii and Terminalia catappa seedlings after 120 days from the date of sowing

\begin{tabular}{|c|c|c|c|c|c|c|c|}
\hline \multirow[t]{2}{*}{ Species } & \multicolumn{7}{|c|}{ Pre-sowing treatment } \\
\hline & Control & $\begin{array}{l}\text { Hot } \\
\text { water for } \\
48 \text { hours }\end{array}$ & $\begin{array}{l}\text { Hot } \\
\text { water for } \\
24 \text { hours }\end{array}$ & $\begin{array}{l}\text { Hot } \\
\text { water } \\
12 \\
\text { hours }\end{array}$ & $\begin{array}{l}\text { Cold } \\
\text { water for } \\
48 \text { hours }\end{array}$ & $\begin{array}{l}\text { Cold } \\
\text { water for } \\
24 \text { hours }\end{array}$ & $\begin{array}{l}\text { Cold } \\
\text { water for } \\
12 \text { hours }\end{array}$ \\
\hline Maesopsis eminii & 64 & 60 & 53 & 60 & 65 & 71 & 66 \\
\hline Terminalia catappa & 72 & 65 & 68 & 70 & 80 & 79 & 78 \\
\hline
\end{tabular}

\section{Shoot Height}

The sowing pre-treatments influenced shoot height development of Maesopsis eminii seeds (Table 1). The tallest length of $7.10 \mathrm{~cm}$ was recorded from seeds soaked in cold water for 24 hours, followed by seedlings from seeds treated with cold water for 12 hours which had an average height of $6.90 \mathrm{~cm}$. The lowest height of $5.30 \mathrm{~cm}$ was achieved from seeds soaked in hot water for 24 hours. Highest shoot length of Terminalia catappa $(8.20 \mathrm{~cm})$ was recorded from seedlings that grew from seeds soaked in cold water for 48, 24 hours and 12 hours. The lowest height of $6.5 \mathrm{~cm}$ was obtained from seedlings that evolved from seeds soaked in hot water for 48 hours. In Maesopsis eminii, the average seedlings total height from seeds pre-treated in cold water for 24,12, 48 hours and control were significantly different $(F$-value $=0.954 ; p=0.046)$ from those treated with hot water. For Terminalia catappa, the average seedling total height of seeds pre-treated with cold water for 48, 24, and 12, and control were significantly different ( $F$ value $=0.969 ; p=0.031$ ) from those treated with hot water.

\section{Number of Leaves}

Pre-treatment (soaking in water) influenced the number of leaves of seedlings of each tree species (Table 2). The average number of leaves were highest (7 for Maesopsis eminii and 5 for Terminalia catappa) in seeds soaked with cold water for 24 and 48 hours after 120 days. This might be due to the involvement of cold water soaking in cell elongation and cell division of meristematic tissues because they determine initial growth and capability of plant to compete for basic needs of nutrients, water and light (Khan et al. 2006).

Table 2. Average number of leaves of Maesopsis eminii and Terminalia catappa seedlings after 120 days from the date of sowing

\begin{tabular}{|c|c|c|c|c|c|c|c|}
\hline \multirow{2}{*}{ Species } & \multicolumn{7}{|c|}{ Pre-sowing treatment } \\
\hline & Control & $\begin{array}{l}\text { Hot } \\
\text { water } 48 \\
\text { hours }\end{array}$ & $\begin{array}{l}\text { Hot } \\
\text { water } 24 \\
\text { hours }\end{array}$ & $\begin{array}{l}\text { Hot } \\
\text { water } 12 \\
\text { hours }\end{array}$ & $\begin{array}{l}\text { Cold } \\
\text { water } 48 \\
\text { hours }\end{array}$ & $\begin{array}{l}\text { Cold } \\
\text { water } 24 \\
\text { hours }\end{array}$ & $\begin{array}{l}\text { Cold } \\
\text { water } 12 \\
\text { hours }\end{array}$ \\
\hline Maesopsis eminii & 5 & 5 & 5 & 5 & 7 & 7 & 5 \\
\hline Terminalia catappa & 4 & 4 & 4 & 4 & 5 & 5 & 4 \\
\hline
\end{tabular}

\section{Discussion}

The effects of pre-treatment on the germination of some tree species are reported by Alamgir and Hossain (2005). However, there is little information on the effect of soaking pre-treatment 
of Maesopsis eminii and Terminalia catappa seeds and the effects on seedling development under nursery conditions. Tree nursery profitability will greatly depend on seed germination, growth and survival in the nursery till planting out or selling time. This study was, therefore, set to determine the most appropriate tree seed soaking pre-pre-treatment method that optimizes seed germination and development under nursery conditions. Tree seed pre-germination treatment studies conducted by a number of researchers have shown that pre-sowing treatments significantly increase seed germination rates (Alamgir and Hossain, 2005, Azad et al., 2010a, b, Olatunji et al., 2013 and Billah et al., 2015). Similarly, Ibrahim and Otegbeye (2004) and Owonubi et al. (2005) attained higher germination success on hard coated tree seeds by soaking in water for 12 hours. Likewise, the findings of this study have revealed that the seeds of Maesopsis eminii and Terminalia catappa had increased germination percentages and germination rates when subjected to the various pre-sowing treatments by soaking in cold water. The study revealed differences in treatment results in the species and with no significant variations among the pre-sowing treatments between hot water, cold water and control. However, pre-sowing treatment with cold water for 24 and 12 hours yielded better germination percentages. It was, however, noted that the pre-sowing treatment of Maesopsis eminii seeds with cold water for 12 hours only accelerated germination process. This is important for maintaining uniform germination and growth in a nursery. The seeds also attained higher germination capacity earlier within 10 weeks compared to the untreated seeds which delayed up to 13 weeks probably due to seed dormancy. There was also intermittent germination (Figure 1 and Figure 2) in the untreated seed lots encouraging non-uniform seed age/growth which is not good for commercial tree nursery (Schmidt 2000, Azad et al., 2010a; b Pipinis et al., 2011).

Pre-sowing treatment enhances rapid and uniform germination of seeds. A number of studies have tried to break seed dormancy in hard coated seeds for enhanced germination percentage and seedling vigour. It has become clear that germination of hard coated tree seeds can be improved after pre-treatment although success of the methods used will depend on tree species (Hossain et al., 2005). Although other pre-sowing treatments exist (Olatunji et al., 2013 and Billah et al., 2015), water pre-sowing treatment is cheaper and more manageable by small scale tree nursery operators in the tropics and yields good results (Hossain et al., 2005 and Billah et al., 2015). The seeds soaked in cold water for 48, 24 and 12 hours had the highest seedling height and vegetative growth (leaves) (El Juhany et al., 2009).

\section{Conclusions}

It is concluded from this study that pre-sowing treatment of hard coated tropical tree seeds with cold water for 12 or 24 hours significantly increases germination percentage and germination rate resulting in uniform seedlings growth. Therefore, dormancy in hard coated tropical tree seeds can be broken by soaking the seeds in cold water for 12-24 hours. Soaking the seeds in water drains inhibitors of seed germination thereby encouraging metabolism of Met which controls and regulates seed germination (Pilcher, 1970).

The result of this study will be helpful for both large and small-scale nursery operators to improve the germination of seeds and income from seedlings sales. The reforestation and afforestation programmes that expect to include such species in their planting programmes will gain access to abundant planting materials from the nursery operators. 


\section{Acknowledgements}

Thanks to the management of National Forestry Resources Research Institute (NaFORRI) for supporting and permitting the study to be conducted in the institute's laboratory and tree nursery. This work was supported by Government of Uganda through research funds by the National Agricultural Research Organization (NARO).

\section{References}

Alamgir M, Hossain MK 2005. Effect of pre-sowing treatments on germination and initial seedling development of Albizicia saman in the nursery. Journal of Forestry Research 16(3): 200-204.

Alamgir, M, and Hossain, M. 2005a. Effect of pre-sowing treatments on Albizzia procera (Roxb.) Benth seeds and initials development of seedlings in the nursery. Journal of Forestry and Environment 3: 53-60.

Alamgir, M. and Hossain, M.K. 2005b. Effect of pre-sowing treatments on germination and initials seedling development of Albizicia saman in the nursery. Journal of Forestry Research 16(3): 200-204.

Azad M.S. Nahar N, Mollick A.S, and Matin M.A. 2014. Variation in Seedling Growth of Tamarindus indica (L.): A Threatening Medicinal Fruit Tree Species in Bangladesh. Journal of Ecosystems Article ID 270956, 9 pages http://dx.doi.org/10.1155/2014/270956

Azad MS, Paul N.K., Matin MA 2010b. Do pre-sowing treatments affect seed germination in Albizzia richardiana and Lagerstroemia speciosa? Frontiers of Agriculture in China. 4(2): 181-184.

Azad, M.S., Musa Z.A. and Matin A. 2010a. Effect of pre-sowing treatments on seed germination of Melia azedarach. Journal of Forestry Research 21(2):193- 196.

Billah M.A.S., Kawsar M.H., Titu A.P., Pavel M.A.A., Masum K.M. 2015. Effect of Pre-Sowing Treatments on Seed Germination of Tectona grandis. International Journal of Bioinformatics and Biomedical Engineering Vol. 1, No. 1, pp. 37-42

Billah MAS, Kawsar M H, Titu A P, Pavel MAA, Masum KM. 2015. Effect of Pre-Sowing Treatments on Seed Germination of Tectona grandis

El-Juhany, L.L., Aref, I.M., Al -- Ghamdi, M.A. 2009. Effects of Different Pre-treatments on Seed Germination and Early Establishment of the seedlings of Juniperus procera Trees. World Journal of Applied Sciences 7(5):616- 624.

Hossain MA, Arefin MK, Khan B.M., Rahman MA 2005. Effects of Seed Treatments on Germination and Seedling Growth Attributes of Horitaki (Terminalia chebula Retz.) in the nursery. Research Journal Agriculture and Biological Sciences 1(2):135-141

Hossain MA, Arefin MK, Khan BM, Rahman MA 2005. Effects of Seed Treatments on Germination and Seedling Growth Attributes of Horitaki (Terminalia chebula Retz.) in the nursery. Research Journal Agriculture and Biological Sciences 1(2): 135-141

Khan, A.A. \& Abawi, G.S., 2006. Integrating matrioconditioning and fungicidal treatment of table beet seed to improve stand establishment and yield. Crop. Sci. 32: $231-237$.

Maguire JD 1962. Speed of germination in selection and evaluation for seedling vigour. Crop science, 2: 176-177

Meyer, A.M., Poljakoff-Mayer, A. 1982. The germination of seeds, Penganen Press Ltd, England, p. 200. 
Morpeth, D.R., Hall. A.M. 2000. Microbial enhancement of seed germination in Rosa corymbifera 'Laxa'. Seed Science Research 10, 489-494.

Olatunji D, Maku J O and Odumefun O P. 2013. The effect of pre-treatments on the germination and early seedlings growth of Acacia auriculiformis Cunn. Ex. Benth. African Journal of Plant Science Vol. 7(8), pp. 325-330

Olvera-Carrilloa Y, Marquez-Guzmana J, Barradas V L, Sanchez-Coronado M.E, OrozcoSegovia A. 2003. Germination of the hard seed coated Opuntia tomentosa S.D., a cactus from the Mexico valley Journal of Arid Environments 55 pp $29-42$

Pipinis E, Milios E, Smiris P, Gioumousidis C. 2011. Effect of acid scarification and cold moist stratification on the germination of Cercis siliquastrum L. seeds Turkish Journal of Agriculture and Forestry 35:259264. 